\title{
Enactments of Integrated, Disability-Inclusive Sport Policy by Sporting Organizations
}

\author{
Andrew M. Hammond Andrea Bundon and Caitlin Pentifallo Gadd \\ University of Essex \\ University of British Columbia
}

\author{
Tim Konoval \\ Deakin University
}

\begin{abstract}
This article critically analyzed the enactment of disability-inclusive sport policies by provincial sporting organizations in British Columbia. Thirty semistructured interviews with managers representing 13 organizations informed the analysis. Findings highlighted how organizational circumstances prompted managers to enact integration policies in novel ways at the regional level. For instance, nondisabled sporting organizations mediated the adoption of integration policies due to the perceived impact on nondisabled programming. In contrast, disability sport organizations resisted integration out of concern that nondisabled organizations could not deliver programming to an equivalent standard. To thwart the perceived integration threat, disability sport organizations developed novel solutions, such as registering themselves as freestanding organizations. Discussion arises as to whether integration is the "gold standard" of inclusion in disability sport. Policy recommendations are also discussed.
\end{abstract}

Governments often view the integration of nondisabled sport and its Paralympic equivalent as a policy panacea that will lead to the harmonious assimilation of people with disabilities into mainstream sporting organizations (Peers, Konoval, \& Naturkach, 2020). Nevertheless, research has found that integration does not equal inclusion and is far from harmonious (Howe, 2007; Townsend, Huntley, Cushion, \& Fitzgerald, 2020). Research that has examined the impact of integrative, disability-inclusive sport policy in Canada has mostly focused on athletes' experiences at integrated sport events, the legacies and impacts of these events on volunteer communities, and the effect of hosting these events on rates of sport participation (e.g., Misener, 2015; Misener, Mcgillivray, Mcpherson, \& Legg, 2015). To the authors' knowledge, analyses exploring the enactment of integrative, disabilityinclusive policies related to programming (as opposed to events) are scarce (cf. Misener, 2015; Peers et al., 2020).

Arguably, there is a need for research that examines the adoption, readjustment, and recontextualization of integrative,

(C) 2022 The Authors. Published by Human Kinetics, Inc. This is an Open Access article distributed under the terms of the Creative Commons Attribution-NonCommercial-NoDerivatives 4.0 International License, CC BY-NC-ND 4.0, which permits the copy and redistribution in any medium or format, provided it is not used for commercial purposes, no modifications are made, appropriate credit is given, and a link to the license is provided. See http://creativecommons.org/licenses/ by-nc-nd/4.0. This license does not cover any third-party material that may appear with permission in the article. For commercial use, permission should be requested from Human Kinetics, Inc., through the Copyright Clearance Center (http://www. copyright.com).

Hammond is with the School of Sport, Rehabilitation and Exercise Sciences, University of Essex, Colchester, United Kingdom. Bundon and Pentifallo Gadd are with the School of Kinesiology, University of British Columbia, Vancouver, British Columbia, Canada. Konoval is with the School of Exercise and Nutrition Sciences, Deakin University, Geelong, Victoria, Australia. Hammond (andrew. hammond@essex.ac.uk) is corresponding author. disability-inclusive policies (e.g., the 2006 Canadian Policy on Sport for Persons with a Disability, see: Department of Canadian Heritage, 2006) at the regional and local level by provincial governments and provincial sporting governing bodies. It is at the regional level where most people first engage with sport and where most "opportunities" are delivered (de Bosscher, Sotiriadou, \& van Bottenburg, 2013; Leonard, 1996). Only a small percentage of athletes will ever compete on a national team or at a national or international event (de Bosscher et al., 2013; Leonard, 1996) or live in a region that hosts a megasport event. Moreover, those individuals who do go on to the elite level will still have spent a considerable amount of their sporting career training with local clubs and regional programs (de Bosscher et al., 2013). Thus, it seems logical to understand the translation, interpretation, and enactment of integration policies at the regional level.

This article reports on findings from a large-scale, 3-yearlong study that sought to explore the inclusion and exclusion of people with disabilities in the Canadian province's sport sector. The study attempted to understand how sporting organizations in Canadian province currently engage people with disabilities in their organizations and programs. Specifically, in this article, we report on the part of the research program that sought to understand how provincial sport organizations (PSOs) and regional disability sport organizations (DSOs) translated; interpreted; adjusted; and/or dismissed integrative, disability-inclusive sport policies to suit their own organizational agendas and priorities (Hammond, Jeanes, Penney, \& Leahy, 2019; Hammond, Penney, \& Jeanes, 2020).

\section{Canadian Sport Policy Context}

In Canada, governments (federal, provincial, and local) have historically highlighted that fewer people with disabilities participate in organized sport compared with the general population 
(e.g., Department of Canadian Heritage, 2006; Jaffer \& Brazeau, 2012). Exact numbers are not readily available (Peers et al., 2020); however, the Canadian Policy on Sport for Persons with Disability estimated people with disabilities comprise approximately $1 \%$ of national sporting organization memberships (Department of Canadian Heritage, 2006, para. 20). Sport Canada responded by developing the Funding Accountability Framework that sought to encourage NSOs to meet specific performance targets (Havaris \& Danylchuk, 2007). This included Sport Canada "set[ting] specific performance targets for the integration of athletes with a disability in their [NSO] programming," while also providing funding for disability multisport organizations (e.g., the Canadian Paralympic Committee, Special Olympics Canada, and the Canadian Deaf Sports Association; Department of Canadian Heritage, 2006, para. 21). The actions of Sport Canada are consistent with those of many other countries that have sought to integrate disability and Paralympic sport where possible (i.e., where an equivalent nondisabled sport governing body is available) in order to increase participation in line with social inclusion governmental agendas (Howe, 2007; Hums, Moorman, \& Wolff, 2003; Kitchin, Peile, \& Lowther, 2019; Misener, Bodin, \& Kay, 2019; Peers et al., 2020).

It is important to note that Canadian sport is delivered through a conflict-ridden network of disparate partners (Comeau, 2013; Dowling \& Washington, 2017). According to Thibault and Harvey (1997), organizations that deliver sports programming in Canada include the federal government, provincial/territorial governments, the education sector, nonprofit single-sport organizations, multisport and multiservice organizations, provincial/territorial sport organizations, and community clubs and leagues. In this study, we are focused on nonprofits at the provincial level (i.e., PSOs) that have historically governed organized sport at the regional level and the provincial organizations responsible for serving particular disability and impairment groups that often offer multiple sports (i.e., DSOs). It is also important to note that Canada has a decentralized federal system of government that prioritizes a fair degree of regional autonomy (generally speaking, Canada is unlike the United Kingdom and Australia and more like Belgium and the United States). Thus, in practice, provincial governments can only be persuaded by national governments to adopt broader policy initiatives, allowing for a fair degree of variation when policies are interpreted and enacted by provincial governments that through various funding and legislative levers have much more direct influence over the direction of the sport sector.

\section{Setting of the Study}

Canada is a federation comprised of 10 provinces and three territories. This study took place in British Columbia (B.C.). Within this province (as is the case for all Canadian provinces and territories), PSOs and DSOs receive funding from the provincial government to sustain their activities. While the funding provided is not the sole source of income for the organizations, it is usually their most consistent source of funding. This is especially the case for organizations that deliver disability sport given the high cost associated with specialized equipment such as sport wheelchairs. In this province, the government administers funding through ViaSport BC (2018).

One of the chief objectives of ViaSport since its inception has been to persuade PSOs to be more inclusive of marginalized groups (such as people with disabilities), while also challenging provincial DSOs to expand their programming to underrepresented people with disabilities (e.g., women and girls, LGBTQI2S communities, marginalized youth, Indigenous peoples, socioeconomically disadvantaged, newcomers to Canada, older adults, and those living in rural, remote, and isolated regions). For example, in the 2017-2018 fiscal year, approximately $80 \%$ of the $\$ 13.4$ million contribution from the Provincial Government Ministry to ViaSport was directed to the annual contribution funding of 51 PSOs and seven DSOs. In total, $\$ 7.83$ million was distributed to PSOs and $\$ 818,000$ distributed to DSOs (viaSport British Columbia, 2018). This paper therefore reports on our study that sought to understand, from an interpretive sociological perspective, how PSOs and DSOs translated, interpreted, adjusted, and/or dismissed the previously mentioned disability-inclusive sport policies at the provincial level to suit their organizational agendas and in response to funding incentives.

\section{Disability Sport Policy Implementation}

Few studies have explored the enactment of integration policy as it relates to sports programming in Canada. To our knowledge, studies have examined the history of integration in swimming (Misener et al., 2019) and the implementation of integration by Athletics Canada (Howe, 2007) in high-performance programs at the national level. Recent work by Peers et al. (2020) has also explored how various athletics organizations, both regional and national, communicate their integration initiatives through websites. Of these, most relevant to our work is Howe's study of integration in Canadian athletics (Howe 2007). Specifically, he drew on extensive ethnographic research and Bourdieu's (1977) concept of habitus to explore the integration of Paralympic athletes into Athletics Canada. He found that while the Canadian public admired success at the Paralympics, Athletics Canada viewed athletes with disabilities as less valuable than their nondisabled peers (Howe, 2007). He argued that under the integration regime at the national level of athletics in Canada, athletes with disabilities were merely accommodated, intermixing of culture, whereby both abled and athletes with disabilities contribute to a new cultural environment, did not occur (Howe, 2007).

Peers et al. (2020) conducted a Foucauldian discourse analysis of the websites of provincial athletics organizations. They found that Athletics Canada is seemingly "fully integrated" at the national level; however, they point to how provision at the local and regional level is much more complicated, delivered through a "patchwork of local and provincial DSOs" (p. 113). They found that athletes with disabilities remain absent or marginalized on most websites. It was at the local level where the visibility of integration and inclusion of people with disabilities was most scarce, with fewer examples of explicit commitments to delivering accessible and inclusive programming available. Peers et al. (2020) concluded by saying that the "integrated parasport model in Canada has not become the bastion of inclusion that it was intended to be" (p. 112). While Peers et al. (2020) have illuminated how different track-and-field organizations enact integration in the online communication of their programs and mandates, and Howe (2007) enhanced the understanding of the enactment of (or lack thereof) integration at the level of national programs, in this study, we sought to expand upon their work by exploring to what extent provincial managers enact policies of integration and/or challenge the marginalization of athletes with a disability in their organizations. As previously stated, this focus on the provincial level is important because it is at this level that most sport opportunities are provided. In the following section, we discuss how we used fused concepts of policy sociology with ableism promoted by Jeanes et al. (2018) to evaluate the enactment of inclusion policy by PSOs and DSOs. 


\section{Policy Enactment Theory}

The sociologist Stephen Ball (1993) defines policy as both text and discourse (Ball, Maguire, \& Braun, 2012). The concept of policy as text refers to the words on paper and the use of precise language to signify meanings (Ball, 1993). According to Ball et al. (2012), the policy as text offers a "heuristic device" for understanding how professionals (such as sport managers) work with policy in their occupations. Policy texts are often written in the first-person plural, emphasizing "we" and "our" to imply an accepted consensus (between the creators and readers of policy) about its prescribed direction of change (Ball et al., 2012). The 2006 Policy on Sport for Persons with a Disability represents a meaningful example of a text that seeks to promote an accepted consensus in integration in disability sport (Department of Canadian Heritage, 2006). As an example, a first-person plural consensus statement in the Policy on Sport for Persons with a Disability is the line: "As Canadians, we recognize how important it is to ensure persons with a disability have the means to reach their potential and participate as full members in our society" (Department of Canadian Heritage, 2006, para 4), implying that to be Canadian is to be inclusive while also being meritocratic.

The other aspect of Ball's conceptual framework, policy as discourse, is derived from Foucault's The Archaeology of Knowledge (1972) and draws our attention to how the power-knowledge relationship influences policy meaning. Ball (1993) adopts Foucault's definition of discourses as "the set of conditions in accordance with which practice is exercised, in accordance with which that practice gives rise to partially or totally new statements, and in accordance with which it can be modified" (Foucault, 1972, pp. 208-209). According to Ball (1993), Foucauldian (1977, 1980) lines of thinking provide an instrument for profound analysis that can help uncover "regimes of truth" (and the emergence and history of these truths) embedded in the policy discourses that govern managerial practices. Turning back to the previous quote of the Canadian disability sport policy, following Ball, arguably there are strong discourses of Canadian nationalism (i.e., anti-Americanism, see Granatstein, 1997) suggesting that, unlike the United States, Canada is both inclusive and meritocratic.

Policy enactment uses two distinct theoretical devices to examine enactment: the four contextual frames (see Table 1 below) and the policy actors and policy work typology (see Table 2 below; Hammond, Penney, \& Jeanes, 2020; Jeanes et al., 2018, 2019). Ball et al.'s (2012) contextual frames helped us imagine how broader social, political, economic, and historical milieus influence how official policy texts are read and enacted in local milieus. Following Ball et al. (2012), we have adapted their four different lenses to the PSO and DSO contexts (situated contexts, professional cultures, material contexts, and external contexts). Table 1 illustrates the adapted lenses.

Ball et al.'s (2012) four contextual frames are thought-provoking heuristic devices that have the potential to extend recent sport policy scholarship and highlight how individual PSOs enact integration policy in the contexts in which they operate by illuminating how budgets, histories, and professional traditions mediate the adoption of policies by actors and organizations.

A key aspect of Ball et al.'s (2012) framework was also exploring how different actors played different policy roles within organizations. Therefore, it was essential to hear the perspectives of different actors within the same organization responding to the same policy issue. The policy actor role typology helped us understand, for example, to what extent a member of the board who may be an inclusion champion or policy entrepreneur might have had a different impression of the organization's approach to inclusion policy compared with a volunteer who delivers programs and, in doing so, adopts the role of policy receiver. In Table 2 , we present our adapted version of Ball et al.'s (2012) the policy actors and policy work typology.

It is important to note that policy actor positions are dynamic and shift depending on the issue. For example, some managers who adopted the cynical critic stance toward integrative, disabilityinclusive policies often shifted to be entrepreneurs or enthusiasts toward other policy issues (e.g., sports performance). The policy actor role one takes to an issue is thus dynamic and situational, influenced by many factors including the individuals' life history, the organizations' history, and external sociocultural influences (Jeanes et al., 2018; Penney, 2013).

\section{Toward a Theory of Policy Enactment in the Sociology of Sport}

In essence, we are following other sociologists of sport (e.g., Hammond et al., 2020; Jeanes et al., 2018; O'Gorman, Partington, Potrac, \& Nelson, 2020) who have adapted and recontextualized Ball's work to interrogate how contexts mediate the enactment of national and provincial policies in Canadian provincial sports organizations (i.e., DSOs and PSOs). Specifically, we have used Ball et al.'s (2012) contextual frames to explore the multiple ways in which policies are enacted at the microlevel (cf. Coakley, 2011, 2016; Skille \& Stenling, 2018) and think more carefully about how, for example, contextual factors related to the financial capacity or professional/institutional historical narratives might mediate the "possibilities and probabilities" (Ball et al., 2012) for disability-inclusive sport. Below we discuss how, following others in the sociology of sport, we have overlaid Ball et al.'s (2012) enactment theory with the critical disability studies concept of ableism to theorize the relationship between policy and managers' practice in relation to the enactment of disabilityinclusive polices in the province of B.C.

\section{Ableism}

Our elucidation of ableism builds on previous work (Hammond \& Jeanes, 2018; Hammond et al., 2019; Hammond et al., 2020)

\section{Table 1 Four Contextual Dimensions of Policy}

Situated contexts (e.g., locale, organizational histories, and membership base)

Professional cultures (e.g., values, manager commitments and experiences, and "policy management" in sporting programs)

Material contexts (e.g., staffing, budget, buildings, technology, and infrastructure)

External contexts (e.g., degree and quality of PSO and NSO support; pressures and expectation from broader policy context (e.g., Sport Canada's Funding Accountability Framework, legal requirements, and responsibility)

Adapted from How Schools Do Policy: Policy Enactments in Secondary Schools (p. 21), by S.J. Ball, M. Maguire, and A. Braun, 2012, Abingdon, UK: Routledge. 
Table 2 Policy Actors and Policy Work

\begin{tabular}{ll}
\hline Policy actors & Policy work \\
\hline Narrators & Interpretation, selection, and enforcement of meanings \\
Entrepreneurs & Advocacy, creativity, integration \\
Outsiders & Entrepreneurship, partnership, and monitoring \\
Transactors & Accounting, reporting, monitoring \\
Enthusiasts & Investment, creativity, satisfaction, and career \\
Translators & Production of texts, artifacts, and events \\
Critics & Monitoring of management, maintenance of counterdiscourses \\
Receivers & Typically associated with managers involved with program delivery: coping, defending, and dependency \\
\hline
\end{tabular}

Adapted from How Schools Do Policy: Policy Enactments in Secondary Schools (p. 21), by S.J. Ball, M. Maguire, and A. Braun, 2012, Abingdon, UK: Routledge.

published elsewhere and informed by Campbell's (2001) definition of ableism as:

a network of beliefs, processes and practices that produce a particular kind of self and body (the corporeal standard) that is projected as the perfect, species-typical and therefore essential and fully human. Disability, then, is cast as a diminished state of being human. (p. 44)

Those who study disability sport have highlighted previously how the socially constructed nature of sport privileges notions of ability that are inextricably linked to normative values of masculinity, physicality, and sexuality (DePauw, 1997; Haslett, Monforte, Choi, \& Smith, 2020; Howe \& Jones, 2006; Promis, Erevelles, \& Matthews, 2001; Silva \& Howe, 2012). Following these works, we would also argue, that even when enactments of elite (and subelite) disability sport are performed, the institutions in which they occur (i.e., within the context of the sports endorsed by the International Paralympic Committee and on the Paralympic Games program) are arguably ableist to their core. Under the conditions of ableism and the normative values that undergird it, normative conceptions of elite sport devalue sport for people with disabilities. Furthermore, ableist norms underpin social structures that produce conditions that lead to the disabling of subjects (Jeanes et al., 2018) and the embodiment of disability and, in some cases, the damaging internalization of ableism (Smith \& Bundon, 2017). Moreover, we argue that unless we are aware of the ableist nature of taken-for-granted sporting practices, we risk reproducing the same structures that see people with disabilities positioned as inferior to nondisabled and as "less legitimate" within traditional sport settings (Howe, 2008; Howe \& Kitchin, 2017). It is by drawing on Campbell's theorization of ableism and Ball's writing on policy as text and discourse that we critically evaluated and investigated how the "naturalistic" exclusion of Canadians with disabilities in PSO-led programs despite decades of promoting and producing policies intended to lead to full integration.

Finally, it is also important to think about how ableism has become inextricably linked with late capitalism in western liberal democracies, such as Canada (i.e., for neoliberal-ableism, see Goodley, 2014; Hammond et al., 2019). First, neoliberalism in sport contexts has provided the "ecosystem for the nourishment of ableism" (Goodley 2014, p. 14). Thus, PSOs and DSOs are shaped in sport by larger social, political, and cultural forces associated with neoliberal-able rationalities and technologies of government (i.e., free market values; Goodley, 2014; Goodley \& Lawthom, 2019). Thus, sport managers and the PSOs and DSOs they represent are encouraged under neoliberal (and neoliberal-able) rationalities of government to become autonomous, enterprising entities who are capable of self-government; intervention from the state is limited and actively resisted (Dean, 2010; Green \& Houlihan, 2006). Thereby, ableist discourses create conditions where sport managers maintain control over public sport funding while simultaneously reinforcing the marginalization of certain groups (including those with disabilities).

\section{Methods}

This paper arose from a 3-year project that explored the inclusion/ exclusion of people with disabilities in the B.C. sport sector. The particular study reported on in this paper critically evaluated the impact of disability-inclusive polices on provincial sporting organizations processes and programming. The research was conducted from a poststructuralist perspective, highlighting multiple interpretations of truth, and thus, we do not claim that our findings can be universal or statistically generalizable. We are therefore comfortable "dwell[ing] with uncertainty and recognize that meaning is generated through interpretation of, not excavated from, data" (Braun \& Clarke, 2021, p. 1).

We used a mixture of maximum variation, snowball, and criterion-based sampling approaches to identify and recruit research participants (Smith, Bundon, \& Best, 2016; Smith \& Sparkes, 2013). Maximum variation was achieved by using a typology of disabilitysport organizations developed by the research team as part of the broader project (see Table 3 for typology definitions) to group all the PSOs and DSOs in the region into "types." We then created a shortlist of organizations that included several of each type and targeted these in our recruitment efforts (maximum variation sampling). In creating the shortlist, we also considered the size of the organizations and their dependence on provincial government funding (most funded to least funded) ${ }^{1}$ (for a more detailed description of the development of typologies, see Table 3 ). This process ensured that we were recruiting and sampling from organizations that were diverse in terms of their role in delivering disability sport programming and the resources at their disposal. Once we had identified organizations that we were interested in engaging, we asked individuals within those PSOs and DSOs to direct us to actors within the organization who had expert knowledge regarding programming for disability and inclusion within that sport. To obtain diverse perspectives from the sampled organizations, we asked already recruited participants to assist in identifying other actors in their organizations whom we should speak to (snowballing sampling). 
Finally, the recruitment criteria ensured that all participants were people aged 18 years and older and were (a) employed as a sport manager by a PSO or DSO, (b) sat on the board of a PSO or DSO as a volunteer sport manager, or (c) a member of a PSO or DSO (i.e., a volunteer coach or local program planner).

Consistent with enactment theory (e.g., Ball et al., 2012), we chose our sampling approach to ensure the representation of various managers working within similar but different institutional environments. It was also essential to hear the perspectives of different actors within the same organization responding to the same policy issue (to understand, e.g., whether a member of the board had a different impression of the organization's approach to inclusion policy compared with a volunteer responsible for programming). See Table 4 for a description of the sample.

To recruit the sample, researchers at our partner ViaSport sent e-mails to the PSOs and DSOs who met the sampling criteria. We described the study as research that sought insights into how PSOs and DSOs in B.C. develop disability-inclusive policy. We also stated that we wanted to hear about managers' readiness to develop disability-inclusive policies further. The result was a recruited sample of 30 people (eight males and 22 females) from 13 different organizations (seven PSOs and six DSOs).

\section{Data Collection}

The focus of this paper is to primarily report on the findings of qualitative semistructured interviews conducted by the first author as part of a large-scale, 3-year-long study that sought to explore the inclusion and exclusion of people with disabilities in the Canadian province sport sector. The first author interviewed participants individually and tape-recorded interviews. Interviews were one to three hours long in duration. We used an interview guide to help facilitate discussion. Examples of questions asked included "What is your role in your sporting organization?" "Can you walk me through the top three priorities for your organization?" "What strategies have you developed and implemented to attract new members with disabilities?" and "What are your hopes and aspirations for inclusive disability programming as far as your organization is concerned?" Follow-up questions and probes were used throughout to elicit deeper insights and to enhance and clarify statements.

\section{Data Analysis and Validity}

We analyzed the study data in line with the previously mentioned flexible qualitative approach, drawing liberally on discourse analytical techniques outlined and applied by Ball et al. (2012) in their work on policy enactment in English schools. In particular, we focused on the ways managers justified their positions toward policies within their organizations and made their programming decisions "sensible, palatable and doable for their colleagues" (Ball et al., 2012, p. 16). Following Ball et al. (2012), we analyzed whether certain disability and inclusion discourses are in circulation within the B.C. sports sector. We related this understanding to the probability and possibility of integrative, disability-inclusive policy enactment in the province. With regard to analyzing and interpreting the data, consistent with our Foucauldian-inspired discourse analytic approach, we used Ball et al.'s (2012) four contextual frames and policy actor typology to help build theoretical lenses to deductively identify patterns in the data using our

Table 3 Typology of Inclusive Provision

\begin{tabular}{|c|c|c|c|c|}
\hline Adaptive & Supportive & Shared & Integrated & Multisport \\
\hline $\begin{array}{l}\text { Parasport pathway does not } \\
\text { exist, but efforts to accom- } \\
\text { modate athletes with minor } \\
\text { impairments can be made. }\end{array}$ & $\begin{array}{l}\text { Programming and services offered do } \\
\text { not lead to sport-specific activities, but } \\
\text { serve more generally in the interest of } \\
\text { creating a supportive environment for } \\
\text { athletes across multiple sports or } \\
\text { activities. }\end{array}$ & $\begin{array}{l}\text { Responsibility to } \\
\text { deliver parasport is } \\
\text { shared across one or } \\
\text { more organizations. }\end{array}$ & $\begin{array}{l}\text { Parasport is fully inte- } \\
\text { grated and included in } \\
\text { nondisabled sport pro- } \\
\text { gramming or activities. }\end{array}$ & $\begin{array}{l}\text { Parasport is unique and } \\
\text { shares no or minimal } \\
\text { commonalities with any } \\
\text { nondisabled sports. }\end{array}$ \\
\hline
\end{tabular}

Table 4 Organizations and Managers Sampled

\begin{tabular}{llcll}
\hline & Organization & Number of managers interviewed & PSO or DSO & Typology of inclusive provision \\
\hline 1 & Athletics & 3 & PSO & Shared \\
2 & Adaptive Snow Sports & 2 & DSO & Multisport \\
3 & Alpine skiing & 1 & PSO & Shared \\
4 & Wheelchair Sports Association & 3 & DSO & Multisport \\
5 & Autism Charity & 4 & DSO & Adaptive \\
6 & Cross-country skiing & 3 & PSO & Integrated \\
7 & Special Olympics & 5 & DSO & Multisport \\
8 & Speed skating & 1 & PSO & Adaptive \\
9 & Sport ability & 1 & DSO & Multisport \\
10 & Swimming & 1 & PSO & Integrated \\
11 & Synchronized swimming & 3 & PSO & Adaptive \\
12 & Wheelchair basketball & 2 & DSO* & Shared \\
13 & Blind sports & 1 & DSO & Supportive \\
\hline
\end{tabular}

Note. PSOs = provincial sport organizations; DSOs = disability sport organizations. *Wheelchair basketball is considered both a PSO and DSO 
adapted definitions (see Table 2). It is important to remember that policy actor roles are dynamic and shift in relation to particular issues (e.g., a policy actor might be an entrepreneur when it comes to nondisabled performance sport but a critic when it comes to inclusive sporting initiatives).

Ontological relativism guided our approach to conceptualizing validity and quality (Smith et al., 2016). Specifically, we used the following criteria to reflexively guide our decisions. We assessed the topic's worthiness ("Can studying the organization of disability sport make a meaningful difference in the lives of people with disabilities?") and the significance of the contribution of the work ("Will this research address a gap in the literature and build upon applied and theoretical understandings of disability sport?"). We challenged ourselves to produce a rigorous account of the data ("Is the data nuanced, and does it provide meaningful insights?"). We strove for internal coherence of the research ("Is the research clearly described, and did the purpose, methods, and findings align?"). We contend that the answer to these questions is yes; however, to engage in a reflexive practice, we drew on a previous approach described by Smith et al. (2016). Following this precedent, the first author of the current study kept a reflexive diary to evaluate prior assumptions held about disability, sport, policy, and ongoing judgments about and interpretation of the data. The other authors acted as "critical friends," providing a theoretical sounding board to explore alternative interpretations as we classified the data into themes (Smith et al., 2016). We have endeavored to provide transparency in all aspects of the work, providing the opportunity for others to judge our research quality and value.

\section{Findings}

In this section, we focus on how local contextual factors mediated by high-performance sport discourses influenced the enactment of integration policies by both PSOs and DSOs and the policy actor positions taken by managers. The first section illuminates how PSOs enacted integration and how managers adopted a critic policy-actor stance concerning integrative, disability-inclusive policy. PSO managers perceived integrative, disability-inclusive sport policies as positive as long as that did not disrupt what they perceived to be the organization's "core businesses." In the second part, we examine how individuals from DSOs also overwhelmingly adopted a critic position toward disability-inclusive sport policy and perceived integration to be a threat, and that integration would decrease the quality of sport provision for athletes with disabilities in the B.C.

\section{Nondisabled Organizations Enactments of Integration}

In our interviews, it is evident that nondisabled organizations desired integration but not at the expense of their "core members." For example, the following quote by Tom highlights that he felt his PSO could provide quality integrative experiences but required significant extra funding to do so:

[full integration has to be] a government directive, there has to be appropriate and effective funding in order for a sport organization to be able to deliver programs and services to Olympic and Para streams from development to high performance. (Tom, critic)

Furthermore, his position was that the pressure on organizations to integrate people with disabilities combined with the lack of funding and clear directives on carrying out the integration project was why there was such variable quality for the delivery of Paralympic programs at the local level:

Right now [integration] is a dog's breakfast [ ... ]. That is why Para development programs struggle, because that integration isn't there provincially and then at the community club level. It is a political issue. (Tom, critic)

When interviewees from five of the PSOs we spoke with identified people with disabilities as members, they often placed them at the margins. Similarly, to what Peers et al. (2020) reported, disability programming was marginalized and made to fit existing nondisabled programming. This meant that organizations such as swimming and athletics added disability events to their programs at provincial-sanctioned competitions and added to existing programming. However, integration entrepreneurs, such as Ashley from swimming, still struggled to gain buyin from the sports' coaches, suggesting that coaches were hesitant to support a swimming's official position when they started providing funding for Paralympic pathways. She stated that it was a "challenge educating our coaches about paraswimming and seeing it not as money coming out of their pockets." She further cited ableist assertions from coaches who saw Paralympic programs as a "drain" of resources from core nondisabled programs. The previous finding related to swimming shows how capitalist enactments of elite sport are ableist (Hammond, Jeanes, Penney, \& Leahy, 2019; Pullen, Jackson, Silk, \& Scullion, 2019; Pullen, Silk, Jackson, Silva, \& Howe, 2020). Specifically, the coaching behaviors described by Ashley are examples of how neoliberalable rationalities of government policy actors (coaches) adopt autonomous, enterprising, self-governing subjectivities. Furthermore, the recounting of Ashley's experiences of promoting parasport within provincial swimming demonstrates how intervention from the state is limited and actively resisted by coaches and other actors within the sports policy ecosystem. Ashley's account of capitalist discourses also manifested themselves in material contextual anxieties relating to budgets, which also led to the mediation of the enactment of integrative, disability-inclusive policies within swimming.

Sports that had no formal Paralympic pathway (e.g., speed skating and synchronized swimming) either did not explicitly cater to people with disabilities (speed skating) or provided novel programming solutions that were not constrained by the Paralympic rules and development structures (synchronized swimming). However, the adoption of creative solutions depended on an employee or volunteer to push a disability agenda as a policy entrepreneur. Even when there were entrepreneurs or inclusion champions, we found the enactment of disability programming in these non-Paralympic pathway sports was precarious.

One such example of a policy entrepreneur enacting disabilityinclusive sport policy without a Paralympic pathway was synchronized swimming. Rebecca (a disability-inclusive policy entrepreneur) spoke of how she developed an integrated adapted synchronized-swimming program where athletes with a disability competed alongside nondisabled teammates in a modified competition. In adapted synchro (the term used by Rebecca), athletes with disabilities were allowed some handicapping and concessions when it came to scoring. These concessions allowed for the athlete's full participation by modifying rules, structures, and norms of the sport. At a cursory glance, adapted synchro appeared to be challenging dominant ableist discourses embedded in 
synchronized swimming. However, the sports executive director adopted the role of a disability-inclusion critic when asked if she would like to develop the adapted program further:

One of the things we are seeing here in [Canadian province] is that we are not necessarily doing things really well yet for whom we have [ ... ] we are looking to be able to offer inclusive opportunities to those who want it, and we are not, right now, looking to grow. (Amy, critic)

The above quote's full implications become clear when one understands that "whom we have" refers to the existing core membership of synchronized swimming. From earlier in this interview and from interviews with others in the organization, it was made evident that the core membership that is overwhelmingly white, female, nondisabled, middle class, and aged 8-24 years and that references to developing or growing programming references providing more opportunities for people with disabilities and males. As our study progressed, it became clear that managers were not going to come straight out and declare that they did not want to grow the number of athletes with disabilities to participate in their sport. However, we argue the actor typology (combined with ableism) allowed us to illuminate exclusionary discourses laden in policy-critics speak. The statement above shows how managers, who were disability-inclusive integration policy critics, were very delicate in responding to questions about the growth of disability sport within their respective organizations (synchronized swimming, swimming, athletics, and alpine skiing).

Managers from one PSO also explicitly suggested that parents of nondisabled athletes did not want their children to participate in programs that fully integrated people with disabilities:

There has been some push back from parents on the personal side of this, almost thinking that because their child was on a mixed-ability team that there was something wrong with their kid, not that it was creating an opportunity for the [athlete with a disability]. (Amy, critic)

Even when we found that one sport had a slightly different approach to being more celebrating and wanting to develop parasport, we found that integration occurred out of a high-performance imperative and with the aim of accessing more funding. Our work found that integration policy was pursued mostly out of material contextual concerns rather than an interest to provide more opportunities for people with disabilities to participate in sport and physical activity. For instance, because cross-country skiing experienced better success in their paraprograms than their nondisabled programs at the elite level (i.e., their Para athletes were winning more medals nationally than their nondisabled athletes), the organization actively prioritized the development of paranordic skiing:

I have attended three Cross Country Annual General Meetings now and it starts off with the able-bodied High-Performance Director giving his presentation on how they are trying to do more with less, because the funding is just so tight and then the ParaNordic High Performance Director will follow that presentation with his own presentation and almost be a little bit sheepish because their funding is quite nice [because] the vast majority of all of our medals for Canada were in [Para] crosscountry skiing and biathlon. (Greg, narrator)

Therefore, the PSO argued that due to the emphasis on funding for medals at the national level (due to funding programs such as Own the Podium), the Paralympic program was privileged within their national organizational context, and this led to a situation where the sport prioritized the development of paranordic skiing over Olympic development. For instance, Greg, a narrator in his organization who took an ambivalent position toward disabilitysport policy, justified the sports fixation on its perceived Paralympic success. He reported that out of the 28 medals won by Canada at the last Paralympic Games, 16 of them were won by paranordic athletes from clubs associated with his PSO. Because of this, disability (to some extent) was celebrated and desirable mostly due to the paranordic program's ability to yield medals and federal funding. Therefore, cross-country skiing enactments of integration were more likely to be recognized, celebrated, and valued by their regional body.

Overwhelmingly, cross-country skiing celebrated disability. Many of the actors we spoke to identified themselves as "disability champions" (i.e., what we conceived to be disability policy entrepreneurs). However, there was a perception from the provincial disability coach whom we interviewed (who adopted a policy-critic position concerning disability inclusion) that "inclusion worked best" when high-performance athletes acquired a disability through injury and then took up cross-country skiing:

If you have the mental high-performance athlete mentality, you can pick up another sport. [ . . . ] Our wrestler, she never cross-country skied before and she picked up the sport, she had that mentality and wrestling and cross-country skiing are very different and within three years she meddled at the Paralympics as well. Mentally, she had that high-performance mental state. (Eva, critic)

In paranordic, disability was most celebrated, and actors within the organization were most entrepreneurial concerning disabilityinclusive policies when performances yielded a high-performance result-highlighting how high-performance discourses mediated enactment (Hammond et al., 2020). Thus, a person's disability status was a criterion to become a high-performance athlete, rather than a sport looking at ways they could better incorporate diversity. Therefore, diversity as a result of disability did not seem to disrupt or challenge the dominant values of the sport (Jeanes et al., 2018; Spaaij et al., 2014). This echoes Peers et al. (2020) and Hammond and Jeanes (2018) who found that the "least disabled" are more likely to experience inclusion and that disability is most readily integrated when it can be done so in a way that does not disrupt or challenge the dominant values of the sport (Jeanes et al., 2018; Spaaij et al., 2014).

\section{Disability Sports Organizations "Resistance" to Integration}

In this study, 11 managers representing four DSOs argued against integration. One DSO (wheelchair basketball) supported reverse integration (i.e., the inclusion of nondisabled athletes in wheelchair basketball) but not the notion that their sport be subsumed within a mostly nondisabled PSO. Managers from two DSOs felt it was important that their athletes have access to both segregated and integrated opportunities throughout different stages of their development and athletic careers. Both Adaptive Snow Sports and Autism Charity felt that DSOs had a critical role in supporting athletes' needs with specific impairments and assisting these athletes to navigate to the Canadian province sport sector. As such, DSO managers we interviewed were entrepreneurial about promoting their organizations but, apart from Autism Charity and Adaptive Snow Sports, were primarily passionate critics 
concerning current enactments of integrative, disability-inclusive policies in B.C., except for different reasons compared with their PSO counterparts. Within this next section, we demonstrate how managers working from within DSOs were vocal critics of integration and actively resisted programming initiatives and defended segregated programming. Managers resisted integration for two fundamental reasons: (a) they believed there would be a significant decline in the quality of services provided to people with disabilities, and (b) they perceived there to be more value in their organization taking on the role of high-performance sport provider for their specific impairment group.

One of the managers we spoke with, Allison, a high-ranking manager and integration critic at a DSO, pointed to how for much of her 20-plus-year career, she was an "advocate for integration" but argued that, in practice, handing over control to nondisabled organizations would lead to a decline in quality opportunities for people with disabilities:

For me, the test has always been if we move a sport over to the able-bodied equivalent, will there be a loss of service, quality, and voice for those athletes. (Allison, critic)

Allison tells the story of her interactions with her counterpart at the nondisabled organization who would likely take responsibility for Allison's programming should integration be fully enacted. One of Alison's main points of contention was that her DSO receives approximately $25 \%$ of their funding from the government and uses their charitable status to raise the other $75 \%$ from donors and other grant programs. Under integration, that government funding would be transferred to the PSO now responsible for providing the parasport programming - but the PSO would not have the same commitment or potential to raise the other $75 \%$ of the funds.

[For instance, I asked the ED of a PSO] "OK, so if you were to take on $\mathrm{X}$ sport tomorrow, would you be able to do this scope of programming and would you be able to commit this amount of funding, given that $25 \%$ of it comes from government." And he flat out said no, "can't do it." He said: "We would take the government money and we would use that and go forward." I said: "I cannot in good conscience then say go ahead [with integration], knowing that the program is going be cut to a quarter of what it is right now." (Allison, critic)

In this study, it is plausible to argue that both Alison and her PSO counterpart are right. It is highly likely that PSOs would not be able to offer the full range of programming and services currently provided by the DSO without the government increasing their contribution in order for them to provide quality integrated opportunities.

Indeed, upon further analysis, it became apparent that what the DSOs were resisting was not integration per se. Instead, DSOs were concerned that the enactment of national and provincial integration policies would have a detrimental impact on the individual athletes' experiences while allowing PSOs to claim they were improving inclusion and thereby access national funding schemes such as Sport Canada's Funding Accountability Framework. In their view, the DSOs had an essential role to play in connecting the athletes with disabilities to a community of others with similar impairments and providing support specific to their needs. For example, Lisa, a passionate integration critic from a DSO, had this to say:

My personal opinion on that is that I don't think we will ever get a $100 \%$ integration happening for athletes with disabilities. I don't think that it is clubs not stepping up to what they need to do, I think that the PSOs and national sport organizations don't understand all the various factors that impact an athlete with a disability getting them involved in post and unless you are in it, I don't think you quite understand it fully. And so, again back to that positive first experience and ensuring that the athlete with a disability does not feel excluded, does not feel that they are the only individual in the club. There is so much value that comes from social connection and engaging with other athletes with a disability. Within [Wheelchair Sports] we are supportive of integration if it is done properly. (Lisa, critic)

Both DSOs and PSOs understood that they were operating in an environment shaped by external and material contexts that promote specific visions for integration. They were thus creative in finding productive solutions within the current Canadian sport policy milieu to ensure their organizations' continued viability. For example, Frank, a manager working in a DSO, explained the arrangement his organization has with the hockey PSO whereby the DSO pays the PSO membership fees for all their sledge hockey players so that the PSO can report back to their national organization that they are compliant with Sport Canada's Funding Accountability Framework:

[Hockey] does not have the capacity to take on programming for sledge ... . They are a bigger organization than we are. It could be down to knowledge, maybe it is the comfort level of working with athletes with disabilities at the organizational level. There may be individuals within the organization that may have that comfort level but at the organizational level they may not. They are quite comfortable with us taking that on and working with them and sharing data. They share data with Hockey Canada and say "yes, we have this many members playing sledge hockey." (Frank, narrator/critic)

In this above example, Frank, a narrator/critic of integration policy, demonstrates how two organizations have reached an arrangement that leads to integration on paper while maintaining segregation regarding how the programs are delivered. In this instance, the arrangement is seen as mutually beneficial in that it allows the DSO to continue their operations and ensure that the quality of the programming delivered to their athletes is at the standard they would expect while simultaneously allowing the PSO to meet the external contextual criteria set by their government funders to provide inclusive sport opportunities.

However, not all DSOs were equally satisfied with these arrangements, and some were explicitly concerned that an increasing amount of their time and resources were being co-opted by PSOs who needed to deliver integrated programming to satisfy funding requirements. Sam, a critic and a DSO manager, explains how changes to the provincial funding structure meant that they were frequently asked to donate labor and assets to bolster PSOs with no parasport pathways to meet their targets:

[Since PSOs have been] marked on and rated on their inclusivity to people with disabilities, the number of inquiries and requests and demands from some of those PSOs is huge: "Can we rent a few chairs from you because are going to do a Have A Go with wheelchair badminton at our national championships or we want to start adaptive lacrosse." We have had three meetings, and we have had a Have A Go session with them, and we think we found a route through Let's Play. We have probably now spent 8 hours of our time helping those guys. I looked at my mission statement-it does not say anything about adaptive lacrosse. (Sam, critic) 
Sam's frustration was echoed by others in the DSO sector who felt that increasingly they were expected to support other organizations (external contextual frame) to meet their integration targets, which in turn was taking them away from their own organization's operations and core business (material contexts). Furthermore, many of the PSO's requests for support were poorly thought-out or were unsustainable in the long term.

In response to this situation, we observed that some DSOs had found a third way. Rather than partnering with PSOs or putting themselves in a position of serving PSOs, they were instead entrepreneurial in transforming their organizations to become PSOs in their own right. That is to say, they were building capacity to deliver both the supports for individual athletes with disabilities and the programming and pathways of a high-performance sport organization. An example of creative policy entrepreneurialism to critique integration was through our evaluation of the activities of wheelchair basketball, an organization with roots as a DSO (i.e., developed to support wheelchair sports) that has more recently become the authority and provider for the sport of wheelchair basketball in the region.

Being our own PSO gives us a different status [with different funding bodies], so we are able to apply for more funding and different grants having our own status as a PSO and charitable organization. That was the motivation for [becoming a PSO]. (Hannah, critic/entrepreneur)

As the critic/entrepreneur from wheelchair basketball argued above, they got the best of both worlds when it came to funding. They were able to run charity fundraisers and events and draw on corporate and philanthropic funds to support their programming. However, they also were complicit in producing ableist discourses by seeking to market themselves as a legitimate bonafide sports program when it came to applying for sports-based grants from the provincial government. As Misener and Darcy (2014) have argued elsewhere, people with disabilities should have the choice between participating in sports specifically for people with disabilities and integrated offerings. Arguably in the setting of this study, we found to some extent that DSOs were complicit in politicking that led to a form of social closure that constrained the choices of people with disabilities in the province to segregated sporting settings. Therefore, DSOs who adopted the strategy of positioning themselves as normative sporting organizations were at risk of perpetuating ableist thinking that only normative ways of doing sport are legitimate. Indeed, it would appear that sports organizations that evolved out of the DSO structure to become more "PSO-like" would lose the most if integration was mandated and nondisabled basketball was to absorb them into their broader organizational remit because it would likely mean that these organizations would cease to exist.

\section{Discussion and Conclusions}

This research has shed new light on enacting integrated disabilitysports policies at the regional level in Canada. At a broad level, our work extends on the current body of Canadian integrative, disability-sport literature that has primarily focused on the legacy and impact of integrated sport events (e.g., Misener, 2015) and addresses the impact and implications of integration policies in terms of sport programming. Our findings add weight to previous research led by Peers et al. (2020) that highlights how integration does not always lead to equity or equality at the provincial level. Our study thus prompts scholars and policymakers to think more about how they could reimagine inclusion in disability sport to align with choice and the participants' needs rather than creating a one-size-fits-all model for all involved (Misener \& Darcy, 2014). Moreover, our study echoes what has long been known at the national level in Canada (e.g., Athletics Canada, Swimming Canada; Howe, 2009, 2013) while also adding weight to findings that have explored integration at the provincial level. Furthermore, we build on the work of Peers et al. (2020) who investigated what was being offered (or more accurately not offered) at the provincial level and offer a picture of why and how integration is resisted.

Governments (federal, provincial, and local) have lamented that people with disabilities do not seem to participate in organized sport as regularly as those in the general population (e.g., Department of Canadian Heritage, 2006). Sport Canada developed policies such as the Funding Accountability Framework to integrate disability and Paralympic sport where possible (where an equivalent abled-bodied sport governing body is available) to increase participation. In line with Ball et al.'s (2012) enactment theory, there have been unintentional consequences of national integration policy at the provincial level. We highlighted how organizations such as for hockey have appeared to draw up and enact creative solutions to appear integrated on paper. However, as Frank highlighted above, hockey, at least in B.C., is still primarily a segregated sport with a separate PSO and DSO structure. Our findings highlight that sporting organizations have become very adept at learning how to present themselves as more integrated. However, there is little evidence to suggest these changes have led to more people with disabilities participating in sport. The general lack of publicly available sport participation statistics in Canada also makes it difficult to understand the impact of disability sport policy on participation.

Our findings suggest that at a regional level, drawing on Ball et al. (2012), contextual frames (see Table 1), and the policy-actor typology influenced the positions participants took to various elements of disability-integrative policies. Here, we saw contextual factors shaping the types of policy solutions enacted against the backdrop of federally mandated integration policy. For instance, nondisabled sporting organizations mediated the adoption of integration policies due to the perceived impact on their nondisabled high-performance agendas (i.e., professional cultures, material, and external contexts). PSOs unanimously valued high-performance sport and only championed integrative policies when they perceived they aligned with high-performance sport discourse and delivered additional medals and funding. In contrast, organizations in this study that viewed disability sport programming as a threat toward high-performance sporting imperatives (e.g., athletics, synchronized swimming) enacted policies of integration that minimized their involvement in disability sport. Nondisabled PSOs thus sought to retain resources for their existing programs and existing membership (i.e., who they perceived to be their "core members").

In contrast, DSOs and their creative entrepreneurial critics resisted integration out of concern that nondisabled organizations could not deliver the same quality of programming for athletes with disabilities (professional cultures and material contexts). DSOs primarily saw impairment knowledge as a defining aspect of their professional cultures (e.g., blind sports, wheelchair sports, ability sports). To some extent, material considerations (e.g., budgetary concerns related to the quality of service) informed DSO decisionmaking and led some managers to resist calls to integrate, and some PSOs argued that integration would lead to a decline in the quality of disability-sport programming in the region. In many ways, DSOs badged themselves as disability experts and linked their professional cultures to quality experiences. 
Our findings have thus called into question the notion that integrating nondisabled sport and its Paralympic equivalent is a policy panacea that will lead to harmonious integration. Our findings add to the overwhelming body of evidence that reports placing diverse individuals into the same contexts as nondisabled people does not automatically result in the broader community sport sector adopting more inclusive philosophies or attitudes (Howe, 2007; Jeanes et al., 2018; Peers et al., 2020). Thus, we argue, integrative, disability-inclusive policy enactments are unlikely to improve the experiences of athletes with disabilities below the elite level (or even at the elite level when considering previous findings by Howe, 2007).

Another aspect where we have advanced knowledge and theory in the sociology of sport is by revealing the multiple dimensions of resistance in organizational settings by not only thinking about the multiple ways in which organizations can resist diversity (cf. Spaaij, Knoppers, \& Jeanes, 2020), but by showing how multiple agendas can be enacted in the name of inclusion. Similar to Phoenix and Smith (2011), who found in their study of older adults that participants' experiences did not fit with stereotypical assumptions about decline and deterioration in older age, our participants showed how some nondisabled organizations actively resisted broadening participation of people with disabilities (athletics and swimming) and worked to resist exclusion to promote novel inclusive forms of inclusive sport (synchronized swimming). Also, we were able to show how the disability sport sector in B.C. have been actively able to convince their government and primary funding body that segregated disability sport might actually be more inclusive (unlike their counterparts in Ontario, the United States, the Netherlands, and Australia).

This study intended to only focus on one Canadian province. The majority of our participants reside in the largest metro-region (i.e., Metro Vancouver). Therefore, we are cautious about proclaiming that we can speak for all the sport organizations working in a geographically vast, diverse, and complex region. We would also highlight that our research team had an affiliation and partnership with one of the key agencies involved in funding sport (or administering government funding in sport) and that members of the research team were employed by the agency (ViaSport B.C.). While every effort was made to assure PSOs and DSOs that our research was not linked to funding decisions but rather part of the sector's long-term strategy to better understand what is needed to promote inclusive sport practices, the association undoubtedly influenced and shaped what participants said to us. We argue future research is required to explore the enactments of integration in and across multiple jurisdictions across Canada and between jurisdictions. While the particular configuration of sport delivery (organization, policy, and funding) is unique to each country, what remains more constant is the requirement that there be some level of governance and coordination at the regional level (to organize clubs, distribute funding, manage facilities, and deliver events). We argue that other scholars and policymakers may be able to glean insights relevant to their locales. Following Smith (2018), we argue that when our work is read in conjunction with that of others, we would hope generalizability might be grasped on the basis of recognition of similarities and differences to which other sociologists of sport may be familiar (such as the work of Peers et al., 2020) and that there might be some transferable generalizability where others can infer or translate our findings to other contexts, such as Adapted Physical Education (cf. Haegele, 2019) or other national or provincial contexts.
In total, we found that enactments of integration are a deeply flawed project when it comes to producing inclusive outcomes. Our findings call into question this view and prompted us to think more deeply about what is needed to ensure inclusion in an integrated paradigm. We argue that integration in and of itself is unlikely to lead to more inclusive outcomes for people with disabilities. Below we discuss some preliminary thoughts about the attitude or philosophical change to bring about inclusion.

In thinking about practical implications that will bring about inclusion, it is clear that if integration is a desirable outcome, governments should make efforts to protect the impairment specific knowledge of DSOs that lead to safe, welcoming, and accessible environments. As Townsend et al. (2020) have highlighted elsewhere, PSOs in our study sought to push disability "into the background of the collective [managerial] consciousness" (p. 354). Thus to some degree, this research confirmed DSOs' arguments that under integration, policymakers risk disregarding impairment knowledge, echoing DePauw's (1997) previous notion of the "invisibility of disability." Therefore, governments should also consider providing new funding to steward inclusion when DSOs and PSOs work in partnership. However, we argue that at the moment, PSOs and NSOs that are already experiencing long-term austerity are seeking out integrated outcomes to secure more funding (the business imperative; Spaaij et al., 2014). Rather than acting out of some moral imperative tied to social justice (i.e., we should integrate and include people with disabilities because it is "the right thing to do;" Spaaij et al., 2014), current actions seem to be informed by a business imperative (Spaaij et al., 2014). Thus, the push for inclusion is arguably putting stress on DSOs because governments and PSOs are not accounting for or resourcing the extra time and labor required to facilitate these partnerships. Instead of being parasitic (one organization providing a service so that another can thrive but often at the expense of their own operational mandate) or competitive (one organization seeking to gain advantage over another in competition for scarce resources), we suggest that one potential novel path forward is finding new ways of funding DSO-PSO partnerships to foster collaboration and coordination of efforts to maximize the creation of new, quality sport opportunities for people with disabilities.

\section{Acknowledgment}

The authors acknowledge the two anonymous reviewers whose thoughtful comments greatly enhanced the manuscript. The authors are very grateful for the assistance during these challenging times. This research was funded by a Social Science and Humanities Research Council of Canada Partnership Development Grant titled: Level the field: Disability inclusion in sport (8902016-0014) and MITACS. A.M. Hammond completed the empirical work for this article during his postdoctoral fellowship at the University of British Columbia. C. Pentifallo Gadd wishes to declare that at the time of submission, she was engaged as a contractor with viaSport BC and Sport Canada. The authors would like to acknowledge the contribution of Shawna Lawson (viaSport) for her thoughts and feedback on a draft version of this manuscript and for the contribution to the development of the study as an industry partner.

\section{Note}

1. Dependence on provincial-level government funding was deemed to be of interest as funding is one of the ways that governments can ensure compliance with policies and legislation. 


\section{References}

Ball, S.J. (1993). What is policy? Texts, trajectories and toolboxes Discourse: Studies in the Cultural Politics of Education, 13(2), 10-17. doi:10.1080/0159630930130203

Ball, S.J., Maguire, M., \& Braun, A. (2012). How schools do policy: Policy enactments in secondary schools. Abingdon, UK: Routledge.

Bourdieu, P. (1977). Outline of a theory of practice. Cambridge, Cambridgeshire: Cambridge University Press.

Braun, V., \& Clarke, V. (2021). To saturate or not to saturate? Questioning data saturation as a useful concept for thematic analysis and samplesize rationales. Qualitative Research in Sport, Exercise and Health, 13, 201-216.

Campbell, F.A.K. (2001). Inciting legal fictions-disability's date with ontology and the ableist body of the law. Griffith Law Review, 10, 42.

Coakley, J. (2011). Youth sports: What counts as "positive development?" Journal of Sport and Social Issues, 35(3), 306-324. doi:10.1177/ 0193723511417311

Coakley, J. (2016). Positive youth development through sport: Myths, beliefs, and realities. In N.L. Holt (Ed.), Positive youth development through sport (2nd ed., pp. 21-33). New York, NY: Routledge.

Comeau, G.S. (2013). The evolution of Canadian sport policy. International Journal of Sport Policy, 5(1), 73-93. doi:10.1080/19406940. 2012.694368

de Bosscher, V., Sotiriadou, P., \& van Bottenburg, M. (2013). Scrutinizing the sport pyramid metaphor: An examination of the relationship between elite success and mass participation in Flanders. International Journal of Sport Policy and Politics, 5(3), 319-339. doi:10. 1080/19406940.2013.806340

Dean, M. (2010). Governmentality: Power and rule in modern society (2nd ed.). London: Sage.

Department of Canadian Heritage. (2006). Policy on sport for persons with a disability. Retrieved from https://www.canada.ca/en/canadianheritage/services/sport-policies-acts-regulations/policy-persons-withdisability.html

DePauw, K. (1997). The (in)visibility of disability: Cultural contexts and "sporting bodies." Quest, 49(4), 416-430. doi:10.1080/00336297. 1997.10484258

Dowling, M., \& Washington, M. (2017). Epistemic communities and knowledge-based professional networks in sport policy and governance: A case study of the Canadian sport for life leadership team. Journal of Sport Management, 31(2), 133-147. doi:10.1123/jsm. 2016-0071

Foucault, M. (1977). Nietzshe, genealogy, history. In D.F. Bouchard (Ed.), Language, counter memory, practice selected essays and interviews by Michel Foucault (pp. 239-297). Ithaca, NY: Cornell University Press.

Foucault, M. (1980). Power/knowledge: Selected interviews and other writings 1972-1977 (C. Gordon, Ed.). New York, NY: Harvester.

Goodley, D. (2014). Dis/ability studies: Theorising disablism and ableism. Abingdon, OX: Routledge.

Goodley, D., \& Lawthom, R. (2019). Critical disability studies, Brexit and Trump: A time of neoliberal-ableism. Rethinking History, 23(2), 233-251.

Granatstein, J. (1997). Yankee go home? Canadians and anti-Americanism. Toronto, OT: Harper Collins.

Green, M., \& Houlihan, B. (2006). Governmentality, modernization, and the "Disciplining" of national sporting organizations: Athletics in Australia and the United Kingdom. Sociology of Sport Journal, 23(1), 47-71. doi:10.1123/ssj.23.1.47

Haegele, J.A. (2019). Inclusion illusion: Questioning the inclusiveness of integrated physical education. Quest, 71(4), 387-397. doi:10.1080/ 00336297.2019.1602547
Hammond, A., \& Jeanes, R. (2018). Federal government involvement in Australian disability sport, 1981-2015. The International Journal of the History of Sport, 35(5), 431-447. doi:10.1080/09523367.2017. 1337000

Hammond, A., Jeanes, R., Penney, D., \& Leahy, D. (2019). "I feel we are inclusive enough": Examining swimming coaches' understandings of inclusion and disability. Sociology of Sport Journal, 36(4), 311-321. doi:10.1123/ssj.2018-0164

Hammond, A., Penney, D., \& Jeanes, R. (2020). Sport coaches as policy actors: An investigation of the interpretation and enactment of disability and inclusion policy in swimming in Victoria Australia. Sport, Education and Society, 25(5), 570-585. doi:10.1080/ 13573322.2019.1628013

Haslett, D., Monforte, J., Choi, I., \& Smith, B. (2020). Promoting para athlete activism: Critical insights from key stakeholders in Ireland. Sociology of Sport Journal, 37(4), 273-282. doi:10.1123/ssj.2019-0174

Havaris, E.P., \& Danylchuk, K.E. (2007). An assessment of sport Canada's sport funding and accountability framework, 1995-2004. European Sport Management Quarterly, 7(1), 31-53. doi:10.1080/16184740 701270329

Howe, P.D. (2007). Integration of paralympic athletes into athletics Canada. International Journal of Canadian Studies/Revue Internationale d'études Canadiennes, 35(35), 133-150. doi:10.7202/040767ar

Howe, P.D. (2008). The tail is wagging the dog: Body culture, classification and the Paralympic movement. Ethnography, 9(4), 499-517. doi: $10.1177 / 1466138108096989$

Howe, P.D. (2009). An accessible world stage: Human rights, integration and the para-athletic program in Canada. Cambrian Law Review, 40, 23-35.

Howe, P.D. (2013). Policy on sport for the disabled. In J. Harvey \& L. Thibault (Eds.), Sport policy in Canada (pp. 295-316). Ottawa, Canada: University of Ottawa Press.

Howe, P.D., \& Jones, C. (2006). Classification of disabled athletes: (Dis) empowering the Paralympic practice community. Sociology of Sport Journal, 23(1), 29-46. doi:10.1123/ssj.23.1.29

Howe, P.D., \& Kitchin, P.J. (2017). Managing paralympic bodies: The technology of classification and its impact on (dis)abled athletes. In S. Darcy, D. Adair, \& S. Frawley (Eds.), Managing the paralympics (pp. 113-132). London, UK: Springer Nature.

Hums, M.A., Moorman, A.M., \& Wolff, E.A. (2003). The inclusion of the Paralympics in the Olympic and Amateur Sports Act: Legal and policy implications for integration of athletes with disabilities into the United States Olympic Committee and national governing bodies. Journal of Sport and Social Issues, 27(3), 261-275.

Jaffer, M.S.B., \& Brazeau, P. (2012). Level the playing field: A natural progression from playground podium for Canadians with disabilities. Retrieved from https://sencanada.ca/content/sen/Committee/411/ridr/ rep/rep07jun12-e.pdf

Jeanes, R., Spaaij, R., Magee, J., Farquharson, K., Gorman, S., \& Lusher, D. (2018). 'Yes we are inclusive': Examining provision for young people with disabilities in community sport clubs. Sport Management Review, 21(1), 38-50. doi:10.1016/j.smr.2017.04.001

Jeanes, R., Spaaij, R., Magee, J., Farquharson, K., Gorman, S., \& Lusher, D. (2019). Developing participation opportunities for young people with disabilities? Policy enactment and social inclusion in Australian junior sport. Sport in Society, 22(6), 986-1004. doi:10.1080/17430437.2018. 1515202

Kitchin, P.J., Peile, C., \& Lowther, J. (2019). Mobilizing capacity to achieve the mainstreaming of disability sport. Managing Sport and Leisure, 24(6), 424-444.

Leonard, W.M. (1996). The odds of transiting from one level of sports participation to another. Sociology of Sport Journal, 13(3), 288-299. doi:10.1123/ssj.13.3.288 
Misener, L. (2015). Leveraging parasport events for community participation: Development of a theoretical framework. European Sport Management Quarterly, 15(1), 132-153. doi:10.1080/16184742.2014.997773

Misener, L., Bodin, K., \& Kay, M. (2019). Governing integration in sport systems: A case study of swimming Canada. Case Studies in Sport Management, 8(Suppl. 1), S39-S44. doi:10.1123/cssm. 2018-0032

Misener, L., \& Darcy, S. (2014). Managing disability sport: From athletes with disabilities to inclusive organisational perspectives. Sport Management Review, 17(1), 1-7. doi:10.1016/j.smr.2013.12.003

Misener, L., Mcgillivray, D., Mcpherson, G., \& Legg, D. (2015). Leveraging parasport events for sustainable community participation: The Glasgow 2014 Commonwealth Games. Annals of Leisure Research, 18(4), 450-469. doi:10.1080/11745398.2015.1045913

O’Gorman, J., Partington, M., Potrac, P., \& Nelson, L. (2020). Translation, intensification and fabrication: Professional football academy coaches' enactment of the Elite Player Performance Plan. Sport, Education and Society, 26, 1-17.

Peers, D., Konoval, T., \& Naturkach, R.M. (2020). (Un)imaginable (Para-) athletes: A discourse analysis of athletics websites in Canada. Adapted Physical Activity Quarterly, 37(1), 112-128. PubMed ID: 31860833 doi:10.1123/apaq.2019-0062

Penney, D. (2013). From policy to pedagogy: Prudence and precariousness; actors and artefacts. Asia-Pacific Journal of Health, Sport and Physical Education, 4(2), 189-197.

Phoenix, C., \& Smith, B. (2011). Telling a (good?) counter story of aging: Natural bodybuilding meets the narrative of decline. The Journals of Gerontology, Series B: Psychological Sciences \& Social Sciences, 66 (5), 628-639. doi:10.1093/geronb/gbr077

Promis, D., Erevelles, N., \& Matthews, J. (2001). Reconceptualizing inclusion: The politics of university sports and recreation programs for students with mobility impairments. Sociology of Sport Journal, 18(1), 37-50. doi:10.1123/ssj.18.1.37

Pullen, E., Jackson, D., Silk, M., \& Scullion, R. (2019). Re-presenting the Paralympics: (contested) philosophies, production practices and the hypervisibility of disability. Media, Culture and Society, 41(4), 465-481.

Pullen, E., Silk, M., Jackson, D., Silva, C.F., \& Howe, P.D. (2020). Extraordinary normalcy, ableist rehabilitation, and sporting ablenationalism. Sociology of Sport Journal. Advance online publication.
Silva, C.F., \& Howe, P.D. (2012). The (in)validity of supercrip representation of Paralympian athletes. Journal of Sport and Social Issues, 36(2), 174-194. doi:10.1177/0193723511433865

Skille, E. ̊., \& Stenling, C. (2018). Inside-out and outside-in: Applying the concept of conventions in the analysis of policy implementation through sport clubs. International Review for the Sociology of Sport, 53(7), 837-853. doi:10.1177/1012690216685584

Smith, B. (2018). Generalizability in qualitative research: Misunderstandings, opportunities and recommendations for the sport and exercise sciences. Qualitative Research in Sport, Exercise and Health, 10(1), 137-149. doi:10.1080/2159676X.2017.1393221

Smith, B., \& Bundon, A. (2017). Disability models: Explaining and understanding disability sport in different ways. In I. Brittain \& A. Beacom (Eds.), The Palgrave handbook of paralympic studies (pp. 15-34). Basingstoke, UK: Palgrave.

Smith, B., Bundon, A., \& Best, M. (2016). Disability sport and activist identities: A qualitative study of narratives of activism among elite athletes' with impairment. Psychology of Sport and Exercise, 26, 139-148. doi:10.1016/j.psychsport.2016.07.003

Smith, B., \& Sparkes, A.C. (2013). Qualitative research methods in sport, exercise and health: From process to product. Abingdon, UK: Routledge.

Spaaij, R., Farquharson, K., Magee, J., Jeanes, R., Lusher, D., \& Gorman, S. (2014). A fair game for all? How community sports clubs in Australia deal with diversity. Journal of Sport \& Social Issues, 38(4), 346-365. doi:10.1177/0193723513515888

Spaaij, R., Knoppers, A., \& Jeanes, R. (2020). "We want more diversity but ...": Resisting diversity in recreational sports clubs. Sport Management Review, 23(3), 363-373. doi:10.1016/j.smr.2019.05.007

Thibault, L., \& Harvey, J. (1997). Fostering interorganizational linkages in the Canadian sport delivery system. Journal of Sport Management, 11(1), 45-68. doi:10.1123/jsm.11.1.45

Townsend, R.C., Huntley, T., Cushion, C., \& Fitzgerald, H. (2020). 'It's not about disability, I want to win as many medals as possible': The social construction of disability in high performance coaching. International Review for the Sociology of Sport, 55(3), 344-360. doi:10.1177/1012690218797526

viaSport British Columbia. (2018). Year-End Highlights 2017-2018. viaSport British Columbia Society. Retrieved from https://www.viasport. ca/sites/default/files/Documents/viaSport_2017-18_YrEndReviewWeb_4C.pdf 